\begin{tabular}{c} 
JCEBT, 5 (1) Maret 2021 ISSN 2549-6379 (Print) ISSN 2549-6387 (Online) \\
JCEBT \\
OEournal of Civil Engineering, Building and Transportation) \\
Available online http://ojs.uma.ac.id/index.php/jcebt \\
\hline
\end{tabular}

\title{
Analisis Stabilitas Lereng Menggunakan Metode Elemen Hingga (MEH) Pada Ruas Jalan Tawaeli - Toboli Km 23 + 700
}

\section{Analysis Slope Stability Using Finite Element Methode In The Tawaeli - Toboli Road Km $23+700$}

\author{
Zainul, Busthan \& Ratna Husain \\ Teknik Geologi, Fakultas Teknik, \\ Universitas Hasanuddin, Makassar, Indonesia
}

Email: zikslahkan@gmail.com

\begin{abstract}
Abstrak
Ruas jalan Tawaeli - Toboli adalah salah satu jalur yang menghubungkan beberapa kabupaten yang ada di Sulawesi Tengah. Dalam rangka meningkatkan kualitas prasarana transportasi tersebut,maka Pemerintah Sulawesi Tengah berencana untuk melakukan pelebaran jalan raya penghubung Kecamatan Tawaeli dan Kecamatan Toboli. Setiap musim hujan, wilayah ini merupakan daerah yang paling sering mengalami bencana tanah longsor yang dapat mempengaruhi transportasi antar daerah, sehingga harus dilakukan penanganan secara serius. Secara geologis daerah ini adalah bagian dari kompleks batuan metamorf yang berfoliasi dan terkekarkan. Salah satu metode untuk menentukan tingkat kerawanan tanah longsor yaitu menggunakan Metode Elemen Hingga dengan dimodelkan menggunakan program Plaxis V. 6 . Hasil analisis faktor keamanan pada kondisi gaya gravitasi adalah sebesar 1,032<1,5 dan kondisi gaya eksternal adalah sebesar 1,004 <1,5. Deformasi akibat gaya gravitasi adalah sebesar 1,92 $\mathrm{cm}$ dan akibat gaya eksternal adalah sebesar $4,93 \mathrm{~cm}$, sehingga dapat disimpulkan bahwa lereng tersebut masuk pada katagori tidak aman.
\end{abstract}

Kata Kunci: Tanah Longsor, Tawaeli - Toboli km 23 +700, Metode Elemen Hingga, Faktor Keamanan.

Abstract

The Tawaeli - Toboli road section is one of the routes connected to several districts in Central Sulawesi. In order to improve the quality of transportation infrastructure, the Central Sulawesi Government plans to widen the road connecting Tawaeli and Toboli Regencies. Every rainy season, this area is an area that experiences landslides that can affect inter-regional transportation, so it must be taken seriously. Geologically, this area is part of a metamorphic rock complex that peels and expands. One method to determine the level of landslide vulnerability is by using the Finite Element Method which is modeled using the Plaxis V program. 6. The results of the analysis of the safety factor in the force conditions are $1.032<1.5$ and the external force conditions are $1.004<1.5$. Deformation due to gravity is $1.92 \mathrm{~cm}$ and due to external forces is $4.93 \mathrm{~cm}$, so it can be said that the slope is in the unsafe category.

Keywords: Landslide, Tawaeli - Toboli km 23 +700, Finite Element Method, Safety Factor.

How to Cite: Zainul. Busthan. \& Ratna Husain. (2021). Analisis Stabilitas Lereng menggunakan Metode Elemen Hingga (MEH) Pada Ruas Jalan Tawaeli -Toboli Km $23+700$. JCEBT (Journal of Civil Engineering, Building and Transportation). 5 (1): 1-8 
Zainul. Busthan. \& Ratna Husain. (2021). Analisis Stabilitas Lereng menggunakan Metode Elemen Hingga (MEH) Pada Ruas Jalan Tawaeli -Toboli Km $23+700$

\section{PENDAHULUAN}

Untuk meningkatkan kualitas prasarana transportasi

Pemerintah Sulawesi Tengah berencana untuk melakukan pelebaran jalan raya penghubung Kecamatan Tawaeli dan Kecamatan Toboli. Jalan raya ini merupakan sarana penting dalam upaya meningkatkan kualitas kehidupan sosial dan ekonomi masyarakat Sulawesi Tengah. Jalan raya ini direncanakan pula untuk menjadi jalan provinsi yang menghubungkan Sulawesi Tengah, Sulawesi Utara, dan Sulawesi Tenggara. (Hanif, dkk. 2017)

Secara geografis, Penelitian ini dilakukan di Kebun Kopi km $23+700$, ruas jalan Tawaeli - Toboli, Provinsi Sulawesi Tengah. Secara astronomis terletak pada kordinat 0॰43'5,57'-0॰43'7,24" LU dan $119^{\circ} 56^{\prime} 43,9^{\prime \prime}$ - 11956’46,55” BT. Secara administratif, daerah penelitian berada di wilayah Kecamatan Uwentiro, Kabupaten Donggala dan Kecamatan Toboli, Kabupaten Parigi Moutong, Sulawesi Tengah.

Tujuan penelitian adalah melakukan analisis stabilitas lereng untuk mengetahui tingkat kerawanan dan deformasi badan jalan pada ruas jalan Tawaeli - Toboli $\mathrm{Km}$. $23+700$ menggunakan Program Plaxis V.6 Kondisi geologi regional poros Tawaeli - Toboli dilihat pada tabel 1. yang berbasis elemen hingga, sehingga dapat menghasilkan sebuah perencanaan penanganan longsoran yang efektif dan tepat secara permanen.

Secara umum morfologi daerah penelitian dibagi menjadi tiga satuan yaitu dataran rendah, perbukitan dan pegunungan. Dataran rendah menempati wilayah yang sempit di Lembah Palu antara Bombaru dan Pakuli dengan tingginya berkisar 0 - 50 meter di atas permukaan laut, dengan lereng sangat landai hingga datar, sedangkan pada wilayah pegunungan bagian timur Lembah Palu membujur dengan arah utara selatan, morfologi ini umumnya berlereng terjal dan memiliki ketinggian 500 meter di atas permukaan laut. (Sukamto, dkk, 1973)

Stratigrafi daerah penelitian tersusun oleh batuan berumur Kapur hingga Kuarter, batuan tertua adalah Kompleks Metamorf Palu (Palu Metamorphic Complex) yang tersingkap pada jajaran pegunungan timur yang diperkirakan berumur Pra-Tersier. Di atas Kompleks Batuan Metamorf terdapat Formasi Tinombo menindih tidak selaras, yang terendapkan pada lingkungan laut dangkal berumur Eosen Tengah hingga Eosen Atas. (Sukamto, dkk, 1973) 
Tabel 1. Kondisi geologi poros Tawaeli -Toboli (Pasific Consultants International Y Yachiyo.,1998)

\begin{tabular}{|c|c|c|c|c|}
\hline $\begin{array}{l}\text { Umur } \\
\text { geologi }\end{array}$ & Formasi & Geologi & Distribusi & Keterangan \\
\hline Holocene & Alluvium & $\begin{array}{l}\text { Pasir, lempung, dan } \\
\text { gravel unconsolidated }\end{array}$ & $\begin{array}{l}1 \mathrm{~km} 100-6 \mathrm{~km} 500 \\
44 \mathrm{~km} 300-45418 \mathrm{~km}\end{array}$ & $\begin{array}{l}\text { Alluvium } \\
\text { terdistribusi pada } \\
\text { dataran rendah } \\
\text { dekat Tawaeli - } \\
\text { Toboli. }\end{array}$ \\
\hline Miocene & Selebes & $\begin{array}{l}\text { Sandstode, } \\
\text { Conglomerat, Mudstone }\end{array}$ & $6 \mathrm{~km} 500-15 \mathrm{~km} 300$ & $\begin{array}{l}\text { Formasi } \text { ini } \\
\text { termasuk weakly } \\
\text { consolidated dan } \\
\text { diklasifikasikan } \\
\text { sebagai material } \\
\text { antara tanah dan } \\
\text { batuan lunak }\end{array}$ \\
\hline $\begin{array}{l}\text { Palaeogene } \\
\text { Period }\end{array}$ & $\begin{array}{l}\text { Batuan } \\
\text { Metamorf }\end{array}$ & $\begin{array}{l}\text { Schist } \\
\text { Gneiss }\end{array}$ & $\begin{array}{l}\text { Schist: } \\
16 \mathrm{~km}-27 \mathrm{~km} \\
32 \mathrm{~km}-35 \mathrm{~km} 700 \\
\text { Gneiss : } \\
15 \mathrm{~km} 300-16 \mathrm{~km} \\
27 \mathrm{~km}-31 \mathrm{~km} \\
35 \mathrm{~km} 700-44 \mathrm{~km} 300\end{array}$ & $\begin{array}{l}\text { Schist terdistribusi } \\
\text { pada sisi Tawaeli } \\
\text { dan Gneiss pada Sisi } \\
\text { Toboli }\end{array}$ \\
\hline
\end{tabular}

Struktur geologi aktif yang melewati yang menghasilkan pergerakan kebawah Kota Palu adalah Palu Koro Fault (PKF) maupun kesamping dari lereng alam yaitu sesar aktif yang melewati Lembah maupun buatan yang memiliki kandungan Palu. Sesar Palu Koro berarah Baratlaut material tanah, batu, tanah timbunan Tenggara sedangkan beberapa buatan atau gabungan dari tanah dan batu. diantaranya ada yang berarah Baratdaya Gerakan massa tanah, batuan atau Timurlaut. (Irsyam, M, dkk, 2010)

Secara geologi, fisiografi Kota Palu berhubungan dengan proses struktur yang terjadi serta jenis batuan yang menyusun Kota Palu, dimana sisi kiri dan kanan Kota Palu merupakan jalur patahan utama, yaitu patahan Palu-Koro serta wilayahnya disusun oleh batuan yang lebih keras dibanding material penyusun bagian lembah (Irsyam, M, dkk, 2010)

Menurut Anugrahadi dkk (2016) longsor juga dapat di artikan sebagai gerakan menuruni lereng oleh massa tanah atau batuan penyusun lereng tersebut. Pergerakan massa tanah ini dapat terjadi pada lereng yang hambat geser tanah atau batuannya lebih kecil dari berat massa tanah itu sendiri. (Varnes, 1978 dalam Highland and Johnson, 2004)

Metode Elemen Hingga (Finite Element Method) adalah salah satu metode numerik untuk menyelesaikan berbagai gerakan tanah atau tanah longsor (landslide) di definisikan sebagai proses problem rekayasa, seperti mekanika struktur, mekanika tanah, mekanika 
batuan, mekanika fluida, hidrodinamik, aerodinamik, medan magnet, perpindahan panas, dinamika struktur, mekanika nuklir, aeronautika, akustik, mekanika kedokteran dan sebagainya. (Susatio dan Yerri. 2004)

Konsep dasar Metode Elemen Hingga adalah apabila suatu sistem dikenai gaya luar, maka gaya luar tersebut diserap oleh sistem tersebut dan akan menimbulkan gaya dalam dan perpindahan. Untuk mengetahui besarnya gaya dalam dan perpindahan akibat gaya luar tersebut, perlu dibentuk suatu persamaan yang mewakili sistem tersebut. Dalam Metode Elemen Hingga keseluruhan sistem dibagi kedalam elemen - elemen dengan jumlah tertentu, selanjutnya dibentuk persamaan sebagai berikut. (Reddy, 2005)

$$
[\mathrm{K}][\mathrm{D}]=[\mathrm{R}]
$$

Keterangan:

$[\mathrm{K}]=$ Matriks kekakuan global

[D] = Matriks perpindahan global

[R] = Matriks gaya global

Proses pembentukan persamaan di atas harus memenuhi kondisi berikut : (Reddy, 2005) a. Kesetimbangan, yaitu kesetimbangan gaya-gaya yang bekerja pada setiap elemen dan keseluruhan material.

b. Kompatibilitas, berkaitan dengan geometri dari material yaitu hubungan perpindahan dengan dan regangan.

c. Persamaan konstitutif dari material, mengenai hubungan tegangan regangan yang merupakan kareakteristik dari material.

Plaxis (Finite Element Code For Soil and Rock Analysis) adalah program pemodelan dan post processing Metode Elemen Hingga yang mampu melakukan analisis masalah geoteknik, dalam perencanaan geologi maupun sipil menyediakan berbagai analisis teknik tentang displacement, tegangan yang terjadi pada tanah dan yang lainnya. Program ini dirancang untuk dapat melakukan pembuatan geometri yang akan di analisis. (Reddy, 2005)

\section{METODE PENELITIAN}

Tahapan penelitian dilakukan sebagai berikut :

1. peninjauan lapangan pada ruas jalan Tawaeli - Toboli km 23+700 sebagai lokasi penelitian 


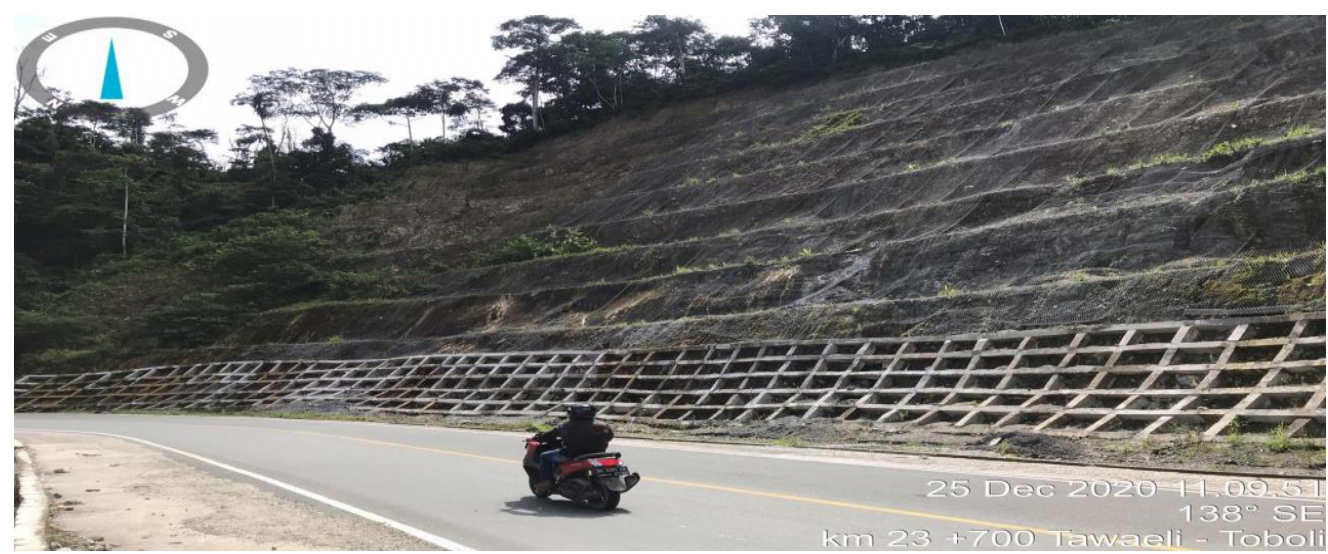

Gambar 1. Lokasi Penelitian poros Tawaeli -Toboli Km 23+700

2. pemodelan dilakukan pada $\mathrm{km}$ dimodelkan dalam program Plaxis V. 6 . 23+700. Tahap ini dilakukan Data-data berasal dari hasil pengamatan umum untuk laboratorium dan pengukuran mendapatkan gambaran yang akan langsung dilapangan.

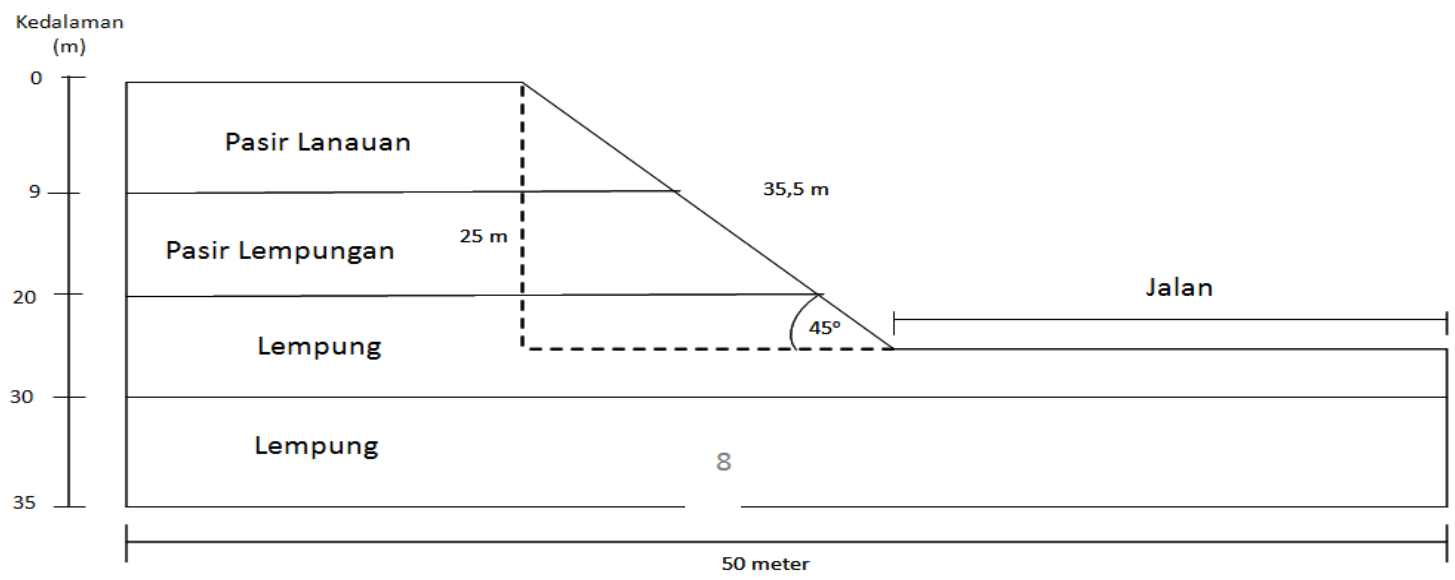

Gambar 2. Pemodelan geomtri lereng dan material penyusunnya

3. program Plaxis V.6 digunakan untuk membantu pengolahan data yang didapatkan dari laboratorium dan survei lapangan, selanjutnya dilakukan input dengan Program Plaxis V.6

4. simulasi elemen hingga program Plaxis V.6 pada pelaksanaan ini disimulasikan dengan model elastoplastis dengan beberapa kondisi antara lain :

a. kondisi gravity loading

b. kondisi vertical loading
5. hasil simulasi program Plaxis V.6 merupakan hasil output dari analisis program Plaxis V.6 yaitu safety factor dan deformasi

6. analisis dan pembahasan

Hasil dan Pembahasan

1.Pemodelan Material

Perilaku tanah dan batuan di bawah beban umumnya bersifat non-linear. Perilaku ini dapat dimodelkan dengan model Mohr Coulomb, model ini mengasumsikan perilaku tanah bersifat 
Zainul. Busthan. \& Ratna Husain. (2021). Analisis Stabilitas Lereng menggunakan Metode Elemen Hingga (MEH) Pada Ruas Jalan Tawaeli -Toboli Km $23+700$

plastis sempurna, dengan menetapkan yaitu modulus young $\left(E_{r e f}\right)$, rasio poisson suatu nilai tegangan batas dimana pada $(v)$, kohesi $\left(C_{r e f}\right)$, sudut geser $(\varphi)$, berat titik tersebut tegangan tidak lagi volume kering $\left(\gamma_{\text {unsat }}\right)$, berat volume basah dipengaruhi oleh regangan. Input $\left(\gamma_{s a t}\right)$ dan permeabilitas $(k)$ pada tabel 2. parameter meliputi 7 buah parameter

Tabel 2. Parameter Tanah yang Digunakan untuk Pemodelan di km $23+700$

\begin{tabular}{|l|l|l|l|l|l|l|l|l|l|}
\hline Lapisan & Jenis Tanah & Tipe & $\gamma_{\text {unsat }}$ & $\gamma_{\text {sat }}$ & $E_{\text {ref }}$ & $C_{\text {ref }}$ & $k$ & $\Phi$ & $v$ \\
\hline \multirow{2}{*}{1} & $\begin{array}{l}\mathrm{kN} / \mathrm{m} 3 \\
\mathrm{kasir} \\
\text { Lanauan }\end{array}$ & Undrained & 11,11 & 16,462 & 6925,06 & 9 & 2,52 E-7 & 22 & 0,3 \\
\hline 2 & $\begin{array}{l}\text { Pasir } \\
\text { Lempungan }\end{array}$ & Undrained & 12,12 & 17,100 & 1500,41 & 8 & $2,12 E-7$ & 35 & 0,3 \\
\hline 3 & $\begin{array}{l}\text { Lempung } \\
\text { Pasiran }\end{array}$ & Undrained & 13,24 & 15,752 & 1666,15 & 12 & $1,72 E-9$ & 24 & 0,3 \\
\hline 4 & $\begin{array}{l}\text { Lempung } \\
\text { Pasiran }\end{array}$ & Undrained & 12,00 & 13,240 & 1103,24 & 14 & $2,52 E-9$ & 40 & 0,3 \\
\hline
\end{tabular}

2. Proses perhitungan

Proses yang ditinjau antara lain, yaitu hitungan beban gravity loading dan vertical loading. Hitungan tersebut sebagai berikut:

a. gravity loading, yaitu beban yang dialami oleh lapisan material berdasarkan gaya grafitasi.

b. vertical loading, yaitu beban lalu-lintas yang berjalan di atas material lereng sebesar 10,203 kN/m² (standar inggris

PPPJJR SKBI 1.3.28.1987).

Analisis kestabilan lereng di km 23 +700 dilakukan dengan 2 kondisi, yaitu kondisi gravity loading dan kondisi vertical loading. Pemodelan analisis stabilitas lereng dilakukan menggunakan Metode Elemen Hingga (MEH) seperti pada gambar 3 dan 4.
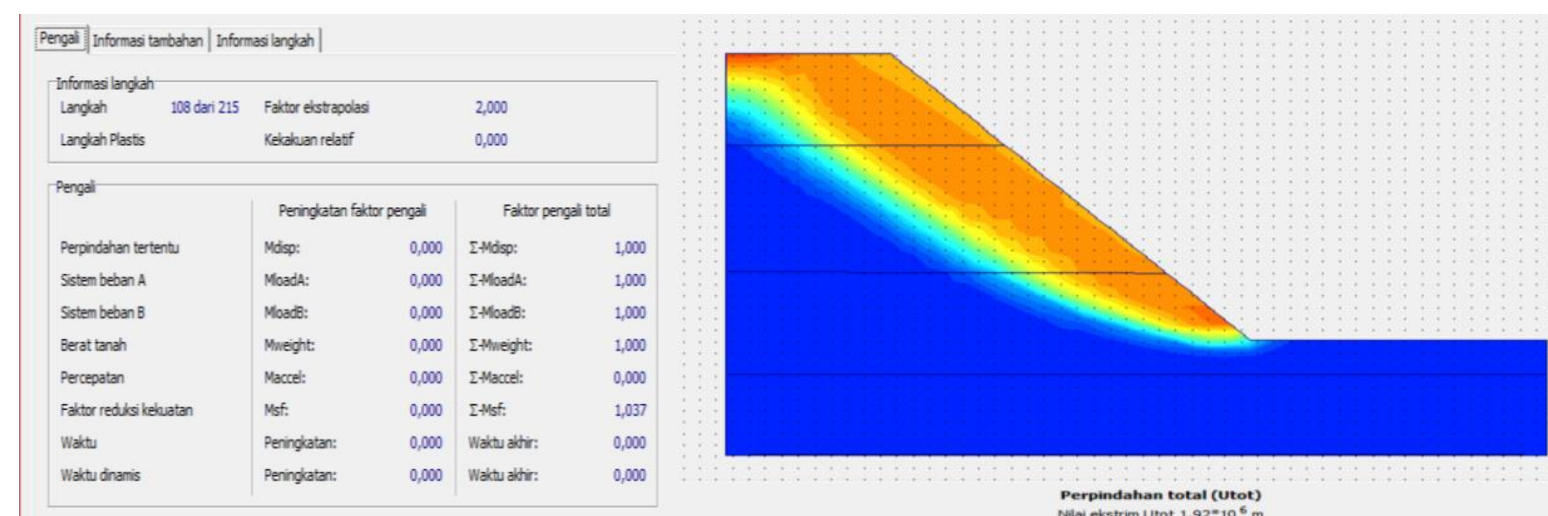

Perpindahan total (Utot)

Gambar 3. Hasil Analisis kondisi gravity loading 


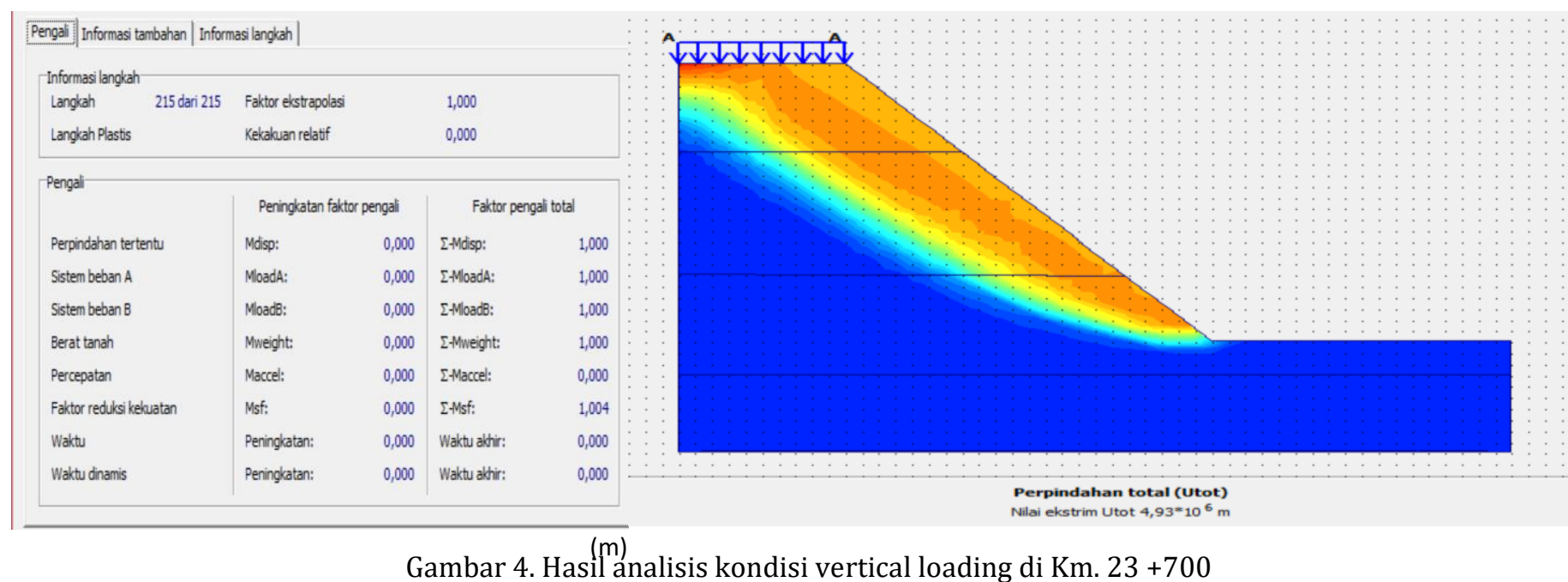

Dari gambar 3 dapat diketahui bahwa safety factor akibat gravity loading adalah sebesar 1,037. Angka ini lebih kecil dibandingkan dengan safety factor minimal untuk keruntuhan yaitu sebesar 1,5. Sedangkan pada gambar 4

\section{KESIMPULAN}

Berdasarkan hasil analisis dan pembahasan tentang analisis stabilitas lereng dalam penanganan longsoran di jalan poros Tawaeli - Toboli km $23+$ 700 maka dapat disimpulkan bahwa pada kondisi normal dan kondisi pembebanan lereng tidak berada di

\section{DAFTAR PUSTAKA}

Anugrahadi, A., Hardiyanti, S. P dan Suryo, N. H., 2016. Terapan Penginderaan Jauh dan Sistem Informasi Geografis Dalam Mitigasi Bencana Beraspek Geologi, Buku 1, Universitas Trisakti, Jakarta.

Hanif, P. G., Wira, C., Reni, H dan Imam, A. S., 2017. Analisis Kestabilan Dan Perkuatan Lereng Massa Batuan Menggunakan Slope Mass Rating Dan Rock Mass Rating Di Jalan Raya dapat diketahui bahwa safety factor akibat vertical loading adalah sebesar 1,004, angka ini juga lebih kecil dari safety factor minimal untuk keruntuhan yaitu sebesar 1,5.

angka aman yaitu $1,037<1,5$ dan $1,004<1,5$. Sedangkan deformasi yaitu sebesar 1,92 cm akibat gravity loading dan sebesar 4,93 cm akibat vertical loading, diharapkan adanya penguatan lereng sehingga safety factor lereng naik jauh di atas safety factor minimum.

Tawaeli - Toboli Km 52 - 64, Palu, Sulawesi Tengah

Highland, L and Johnson, M., 2004. Landslide Types and Processes. USGS Fact Sheet 20043072.

Irsyam, M., Sengara, I, W., Adiamar, F., Widiyantoro, S., Triyoso, W., Natawidjaja, D, 
Zainul. Busthan. \& Ratna Husain. (2021). Analisis Stabilitas Lereng menggunakan Metode Elemen Hingga (MEH) Pada Ruas Jalan Tawaeli -Toboli Km $23+700$

H., dkk., 2010, Ringkasan Hasil Studi Tim Revisi peta Gempa Indonesia, Bandung.

Pasific Consultants International Yachiyo., 1998. Feasibility Study for Tawaeli-Toboli Road volume III, Engineering CO.,LTD.

Plaxis, 2005. Reference Manual

Plaxis Versi 6 Manual Latihan, www.PLAXIS.com
Reddy, J. N., 2005. Solutions Manual For An Introduction to the Finite Element Method, Third Edision. McGraw-Hill, New York

Sukamto, R,., Sumadiradja, H., Suptandar, T., Hardjoprawiro, S., dan Sudana, D., 1973. Peta Geologi Tinjau Lembar Palu, Sulawesi :20152115, Pusat Penelitian dan Pengambangan Geologi, Bandung.

Susatio dan Yerri, I., 2004. Dasar-Dasar Metode Elemen Hingga. Penerbit Andi, Yogyakarta. 